\title{
Research on Teaching Reforms of Electromechanical Transmission Control Based on the Cultivation of Innovative Ability
}

\author{
Hongjun Yang \\ School of Mechanical Engineering, Wuhan Polytechnic University, China \\ Hongjun_yang@163.com
}

\begin{abstract}
Keywords: Electromechanical Transmission Control, Teaching Reform, innovative ability Abstract. Electromechanical transmission control is an important basic course about mechatronics technology for mechanical engineering undergraduate students. Because of low efficiency, the traditional teaching methods for the course can not meet the needs of the current higher education development. In order to improve the students' innovative ability, some teaching reform measures have been put forward, including the construction of the three-dimensional teaching resource, the reforms of teaching method and evaluation. The results show that these measures can markedly improve the innovative ability of the students.
\end{abstract}

\section{Introduction}

Electromechanical transmission control is an important professional foundation course for the students of mechanical engineering, which combines the mechanical engineering and electrical control. Due to the actual production demand, the course is composed of many engineering disciplines, including the mechanical engineering, electronic engineering, electrical engineering, etc. So it has caused some difficulty for the students to master the course knowledge, in which the theory and practice is closely integrated. For this course, it is very important to cultivate practical and creative ability of the students. But there are some problems in the teaching of the course at present, such as teaching time is reduced, students' practical ability is weak, and teaching method is out-dated, and so on.

The 21 st century is the age of science and technology innovation, the cultivation of innovative talents is directly related to the science and technology progress. Therefore, many countries have turned to establish the national innovation system. The high education must meet the need of new the innovative talents, so the old teaching mode of inputting knowledge directly must be reformed and some new teaching methods should be adopted to improve the students' innovation ability. In the past 10 years, many scholars have explored a variety of teaching methods for the course of electromechanical transmission control. For example, in order to overcome the shortcomings of the traditional teaching methods, Xin Xiong and Yihong Ma [1] discussed the teaching methods for the course from some different aspects, including multimedia teaching, classroom interaction teaching, inspire thinking, answering question, and performance evaluation. Xiaohong Li [2] analyzed the existing problems of the theory teaching and practice teaching, and put forward applying the problem-based teaching mode to cultivate of students' innovative ability. Qigen Zhang and Shuangshuang Zhang [3] suggested the reform of the practice teaching and examination system, which had achieved good results.

\section{Course system structure}

The establishment of the course system structure is helpful for the students to find out the logical relationships among the teaching units. As is mentioned before, the contents of the course of electromechanical transmission control are complex and various, including mechanical system dynamics, direct current (DC) motor, alternating current (AC) motor, servo motor, relay contactor control, PLC control, power electronics, speed and position control, etc. It is very necessary to find out the connections between each part and understand the difficult point of teaching. According to the logical relationship between each other of the theory knowledge, the course system structure is put 
forward as shown in Fig.1. First the constitution of the electrometrical transmission system is introduced and the tasks of the system are given. Then the dynamics problem of the system is analyzed by the dynamics equation. In order to solve the problem, the mechatronics servo systems are introduced, which are driven by all kinds of motors, including the DC motor, AC motor, stepping motor and the servo motor. Finally, the basic logical control circuit with relay and contactor is introduced to control the system. Moreover, the advanced control system with PLC (programmable logic controller) is introduced, which can realize complex control task by program.

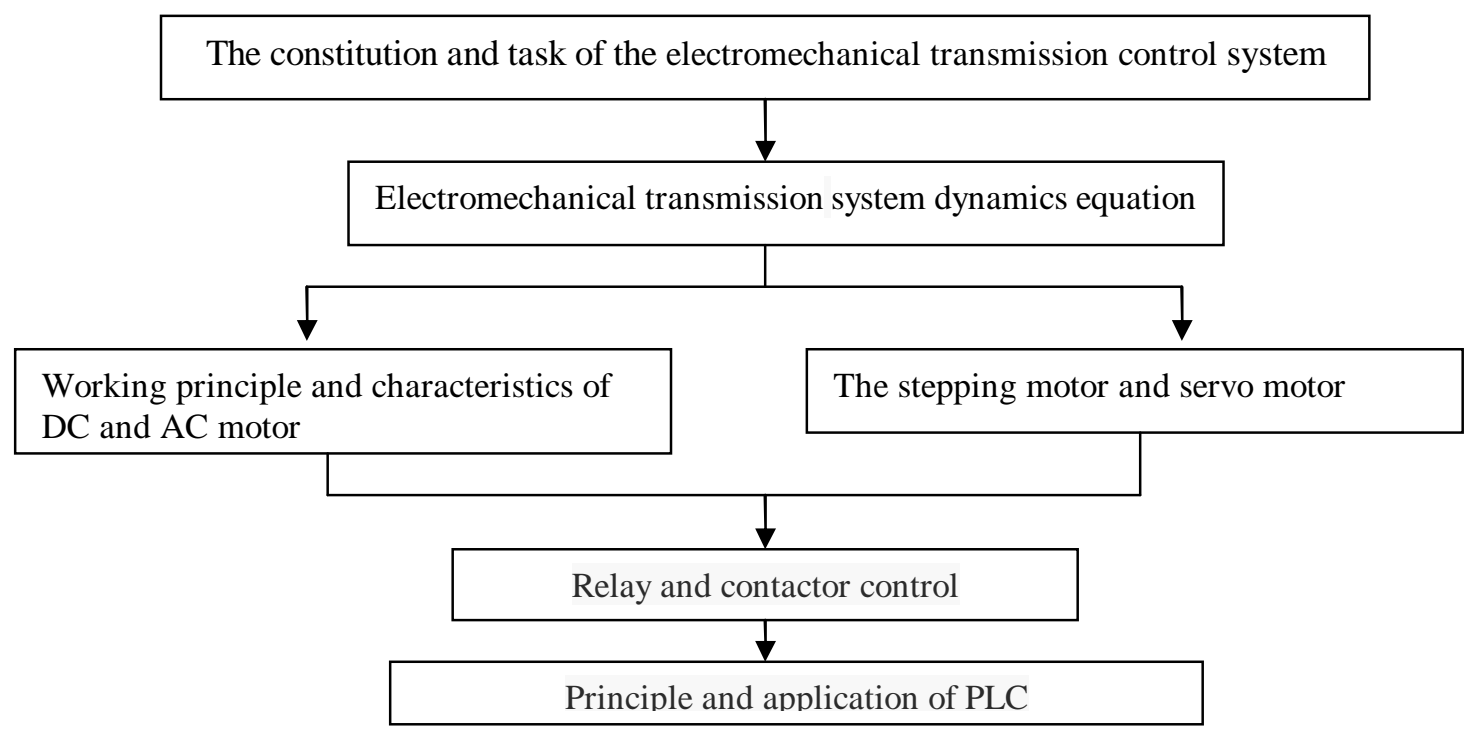

Fig 1. Course system structure

Due to the influence of the mode of traditional teaching and examination, the teacher often emphasize the input of theory knowledge and ignore the cultivation of the innovation ability of the students, which can be proved at practice teaching . Considering that some related courses have been studied, such as electrical theory, electronic technology and mechanical transmission, so during the theory teaching it should simplify the content about motor working principle, dynamic equation calculation and the power electronic devices, but highlight mastering the mechanical characteristics of motor, relay contactor control circuit and the design of PLC control system. According to the latest development of technology, the practice teaching is set on PLC control all kinds of motor and lights control experiment, in order to improve students' practical ability and innovation ability.

\section{The construction of three-dimensional teaching resources}

The three-dimensional teaching resources are the results of modern information technology development, which are important for the modern high education reforms and help to change the teaching concept and mode. It can provide a whole solution of teaching, including meeting the needs of teaching and market maximally, forming the teaching ability of the teachers and promoting the teaching reform. Yunxian Song ${ }^{[4]}$ thought that the three-dimensional teaching resources, which are built to cover the whole the teaching process, take the modern information technology as the tool, the digital teaching software suitable for the remote transmission as teaching materials, the Internet / Intranet as learning and management environment, the autonomous, open and interactive learning as the main learning mode and the media material as the basis. Three-dimensional teaching resources can be defined from three aspects, including the systematic teaching information, digital teaching environment and hierarchical teaching object. Hong Wang ${ }^{[5]}$ thought that the teaching resources for high education constitutes of teaching package, teaching resource database and teaching website with the characteristics of openness, practicality, interactivity and flexibility. 


\section{The reform of the teaching methods}

The traditional teaching pays too much attention to the classroom teaching, but little attention to practice operation. As a result, the students are passive in their learning and are not involved in the process of teaching, which are not suitable to cultivate their innovative thinking and hands-on ability. According to the needs to talents for the current social development, it is very urgent to cultivate the innovative talents by using in a variety of new teaching methods, including, research teaching.

The three-dimensional teaching method is adopted based on three-dimensional resource. According to the integration of advanced design ideas, the most suitable teaching application scheme is designed by the experienced teachers by using the three-dimensional teaching resources, including computer, network and other modern teaching resources. The teaching method can optimize the allocation of the wealth of teaching resource by using a variety of new teaching tool. Moreover, by the network support, the three-dimensional teaching can form the three-dimensional structure with the classroom teaching, network teaching and the practice teaching. Then the teaching target can be realized by the different teaching levels combined CAI (computer-aided instruction) teaching, personalized learning and classroom teaching, and it also can improve students' cognition, emotion, and skill. Moreover, the teaching mode can solve many problems about teaching hard environment, such as the shortage of theory teaching hours and laboratory equipment in practice teaching. Above all, the teaching mode can give full play to the teachers' teaching function and students' subjective initiative study. As the result, it can improve students' practice ability and help them grasp the basic theory of knowledge, which will improve the teaching effect markedly.

Research-based teaching is a new teaching method in the field of high education in recent years. By this method, the teacher takes the cultivation of student's research consciousness, research ability and innovation ability as the goal, guide the student to carry on the investigative study through the research projects in the process of teaching to master the theory knowledge, improve the research ability and innovation ability. Because the course electromechanical transmission control course itself is closely related to the engineering practice, teaching isolated from the scientific research and engineering practice will get half the results with twice the effort. When applied in the course teaching, the research-based teaching can greatly stimulate students' interest and improve the teaching effect significantly. The research-based teaching method includes problem-based teaching, the discussion teaching, the case teaching and the engineering practice teaching.

The problem-based teaching need the teacher create a problem situation according to the teaching content, then give the corresponding problem, and then guide the student to analyze and ponder over the problem, collect and summarize science and technology information martial, explore the method to solve the problem and acquire scientific conclusions and new knowledge.

The discussion teaching need the teacher arrange the teaching content and sequence reasonably firstly. Secondly, the teacher should design the corresponding discussion content according to an important and difficult knowledge. Then the teacher divides the students into several groups and every group analyze and discuss the issue in collaboration and find out the solution, which can cultivate the students' ability of cooperation and divergent thinking.

The case teaching is the method that the teacher prepares the corresponding engineering application cases for certain knowledge at class, then takes step by step, gradually in-depth method to give the solution of engineering problems. During the process, the teacher should ask the students to answer the questions. This teaching method can deepen students understanding of the important theoretical knowledge and the basic steps of engineering design

Engineering practice teaching can let the students directly involve in the practice projects, which can cultivate the ability of practice and innovation of the students and enhance understanding of this subject and cognition. Engineering practice teaching has many methods including course experiment, extracurricular technology production and the teacher research subject. For the course experiment, the teachers need elaborate the contents of the experiment, make good guidance of experiment, guide the student to complete experiment independently, and leave questions to the students to think about. The various levels of extracurricular science and technology production can cultivate the students' learning 
interest and enthusiasm. The students participate in the teachers' scientific research subject directly, which is the most effective teaching method by far and this method can cultivate students' practical ability and scientific research ability.

\section{Reform of teaching evaluation}

The traditional closed-book exam is effective in examining students' grasp of the basic theory, but it also easily makes students attach great importance to the theoretical study but ignore their own improvement of skills. So it is necessary to reform the way of examination and establish all-round evaluation system. For the course of electromechanical transmission control, it is suggested that appraisal ways are divided into the inspection of attendance, performance on discussion, the experimental project completion and the final exam, which can reflects students mastery of knowledge and application ability scientifically. Then each student's overall grade consists of the following four aspects: the test results (60\%), the experiment result accounts for $20 \%$, performance of seminar class accounted for $10 \%$, attendance record $(10 \%)$. As the adoption of the new teaching mode, evaluation of students' academic performance can't take the traditional evaluation mode, multiple types and multi-level evaluation methods should be used which can combine in-class teaching with extracurricular autonomous learning, discussion, engineering practice training and extracurricular science and technology.

\section{Conclusions}

Because the course of electromechanical transmission control involves many engineering disciplines, the traditional teaching method can't meet the needs of the cultivation of current innovative talent. This paper establishes the course system structure by optimizing teaching content. With the help of advanced information technology, the three-dimensional teaching resources are built and some advanced teaching methods are adopted, including three-dimensional teaching and research-based teaching. Finally the evaluation mode is reformed to reflect the student real level. It has been proved that the reforms can improve the students' innovative ability effectively.

\section{Acknowledgements}

This work was financially supported by the Education Research Program of Wuhan Polytechnic University (XZ2015015).

\section{References}

[1] Xin Xiong and Ruhong Ma. A study on teaching method for the course of electromechanical transmission control [J], Industrial \& Science Tribune, No.8,(2009), p.194-195.(In Chinese)

[2]Xiaohong Li. Teaching methods of mechanical and electrical transmission control course based on applied talents' cultivation [J], Journal of Jilin Teachers Institute of Engineering and Technology, Vol. 29, No.4, (2013), p.61-62. (In Chinese)

[3]Qigen Zhang and Shuangshuang Zhang. Some practice of teaching for electromechanical transmission control [J], Science \& Technology Information, No.1, (2014), p.150. (In Chinese)

[4]Yunxian Song, Fanshi Han and Jun Wu. Construction of three-dimensional model of teaching resources[J]. Journal of Electrical \& Electronic Engineering Education, Vol.27, No.2 (2005), p. 100-103. (In Chinese)

[5] Hong Wang. Positioning and system structure of three-dimensional teaching resources [M]. Higher Education Press, Beijing, China, (2004). (In Chinese) 